\title{
CD137L/Epstein-Barr Virus-Targeting Autologous Dendritic Cell Vaccine
}

National Cancer Institute

\section{Source}

National Cancer Institute. CD137L/Epstein-Barr Virus-Targeting Autologous Dendritic

Cell Vaccine. NCI Thesaurus. Code C153097.

A cell-based cancer vaccine composed of in vitro generated, highly potent, CD137 ligand (CD137L)-dendritic cells (CD137L-DCs), pulsed with Epstein-Bar Virus (EBV) antigen peptides, with potential antineoplastic and immunostimulatory activities. Upon administration, CD137L-DCs induce potent CD8+ T-cell responses against EBV+ target cells. DCs stimulated with CD137L enhance cytotoxic T-lymphocyte proliferation and activation to a greater extent compared to non-CD137L-stimulated DCs. 